\title{
Pre-filled Gastroenteral Tube
}

National Cancer Institute

\section{Source}

National Cancer Institute. Pre-filled Gastroenteral Tube. NCI Thesaurus. Code C149859.

Pre-filled tube for the administration of a medicinal product to the gastroenteral tract. 